\title{
A Novel Neural Substrate for the Transformation of Olfactory Inputs into Motor Output
}

\author{
Dominique Derjean ${ }^{1,2}$, Aimen Moussaddy ${ }^{2}$, Elias Atallah ${ }^{2}$, Melissa St-Pierre ${ }^{2}$, François Auclair ${ }^{2}$, Steven \\ Chang $^{3}$, Xiang Ren ${ }^{3}$, Barbara Zielinski ${ }^{3}$, Réjean Dubuc ${ }^{1,2 *}$
}

1 Department of Kinesiology, Université du Québec à Montréal, Montréal, Québec, Canada, 2 Groupe de Recherche sur le Système Nerveux Central, Department of Physiology, Université de Montréal, Montréal, Québec, Canada, 3 Department of Biological Sciences, University of Windsor, Windsor, Ontario, Canada

\begin{abstract}
It is widely recognized that animals respond to odors by generating or modulating specific motor behaviors. These reactions are important for daily activities, reproduction, and survival. In the sea lamprey, mating occurs after ovulated females are attracted to spawning sites by male sex pheromones. The ubiquity and reliability of olfactory-motor behavioral responses in vertebrates suggest tight coupling between the olfactory system and brain areas controlling movements. However, the circuitry and the underlying cellular neural mechanisms remain largely unknown. Using lamprey brain preparations, and electrophysiology, calcium imaging, and tract tracing experiments, we describe the neural substrate responsible for transforming an olfactory input into a locomotor output. We found that olfactory stimulation with naturally occurring odors and pheromones induced large excitatory responses in reticulospinal cells, the command neurons for locomotion. We have also identified the anatomy and physiology of this circuit. The olfactory input was relayed in the medial part of the olfactory bulb, in the posterior tuberculum, in the mesencephalic locomotor region, to finally reach reticulospinal cells in the hindbrain. Activation of this olfactory-motor pathway generated rhythmic ventral root discharges and swimming movements. Our study bridges the gap between behavior and cellular neural mechanisms in vertebrates, identifying a specific subsystem within the CNS, dedicated to producing motor responses to olfactory inputs.
\end{abstract}

Citation: Derjean D, Moussaddy A, Atallah E, St-Pierre M, Auclair F, et al. (2010) A Novel Neural Substrate for the Transformation of Olfactory Inputs into Motor Output. PLoS Biol 8(12): e1000567. doi:10.1371/journal.pbio.1000567

Academic Editor: Piali Sengupta, Brandeis, United States of America

Received May 4, 2010; Accepted November 4, 2010; Published December 21, 2010

Copyright: (c) 2010 Derjean et al. This is an open-access article distributed under the terms of the Creative Commons Attribution License, which permits unrestricted use, distribution, and reproduction in any medium, provided the original author and source are credited.

Funding: We acknowledge a group grant support (8400272) from the Great Lakes Fishery Commission to BZ and RD (http://www.glfc.org/); Individual (15129) and group grants (15176) from Canadian Institutes of Health Research to RD (http://www.cihr-irsc.gc.ca/); and Natural Sciences and Engineering Research Council of Canada support to BZ (http://www.nserc-crsng.gc.ca/). The funders had no role in study design, data collection and analysis, decision to publish, or preparation of the manuscript.

Competing Interests: The authors have declared that no competing interests exist.

Abbreviations: CNS, central nervous system; DLR, diencephalic locomotor region; MLR, mesencephalic locomotor region; MRRN, middle rhombencephalic reticular nucleus; OB, olfactory bulb; ON, olfactory nerve; PT, posterior tuberculum; RS, reticulospinal

*E-mail: dubuc.rejean@uqam.ca

\section{Introduction}

Animals use olfaction in different behavioral contexts such as food seeking, social communication, and reproduction. Motor behaviors, including locomotion, can be generated by olfactory stimulation in several species of vertebrates, including fishes [1], rats [2], humans [3], and lampreys [4]. The highly conserved and stereotyped nature of some of those motor responses suggests a strong neural link between olfactory inputs and motor command centers in the central nervous system (CNS). The neural pathways and the underlying mechanisms responsible for olfactorymotor behavior have only been revealed in one invertebrate species [5]. Here we show the neural substrates for olfactory-motor transformations in vertebrates by using an in vitro lamprey preparation.

It is well established that parasitic sea lampreys increase their locomotor activity towards prey odors [6]. Later in life, pheromones direct movement during upstream migration $[7,8]$ and spawning [4,9]. Fifty-nine chemosensory genes representing three gene families have been identified in the peripheral olfactory organ of the sea lamprey [10], a structure containing the main olfactory epithelium, as well as an adjacent accessory olfactory organ. Accessory olfactory neurons project solely to glomerular neuropil in the medial olfactory bulb $(\mathrm{OB})$, while main olfactory neurons project to both medial and non-medial glomerular neuropil [11]. The GTP binding protein $\mathrm{G}_{\mathrm{olf}}$ is localized in the sensory neurons located in the main olfactory epithelium projecting to the non-medial $\mathrm{OB}$ glomeruli but is absent from olfactory sensory neurons that project into the medial region of the OB [12]. In the sea lamprey, basic amino acids and bile acids, as well as reproductive and migratory pheromones, elicit robust field potential responses in the peripheral olfactory organ [8,13-15]. While the anatomy of the lamprey olfactory system, including the OB projections to the telencephalon and diencephalon, has been partly described [16], the locomotor control system of lampreys is far better understood. Reticulospinal (RS) cells directly activate the spinal locomotor networks $[17,18]$ and act as command neurons for generating locomotor movements. The RS cells receive inputs from the periphery, the spinal cord, and locomotor centers in the forebrain and brainstem, including the mesencephalic locomotor region (MLR [19-21]), a highly conserved neural center controlling locomotion in all vertebrate species. Another locomotor center located in the diencephalon has been described in lampreys [22]. This region, referred to as the diencephalic 


\section{Author Summary}

Animal behaviors, including locomotion, can be driven by olfactory cues, such as pheromones or food sources. The neural substrate (neuroanatomical connections and physiological signals) that permits the transformation of olfactory inputs into locomotor responses is still unknown in vertebrates. In the present study, we identify such a neural substrate in the lamprey. Here, olfactory signals from the outside world are transmitted to the reticulospinal neurons in the lower brainstem, which provide the descending locomotor command to the spinal cord. We found that this circuit originates in the medial portion of the olfactory bulb and that connections are made in the posterior tuberculum, a ventral diencephalic structure. These inputs are then conveyed to the mesencephalic locomotor region, known to project extensively to brainstem reticulospinal neurons and thereby activate locomotion. Our results illuminate a specific dedicated neural substrate in the brain of lampreys that underlies olfactory-motor responses, which is activated by both food-related or pheromonal olfactory cues. It will be of interest to determine whether such a pathway is preserved in all vertebrates. locomotor region (DLR), also projects directly to RS cells. The exact contribution of MLR and DLR to locomotor control has not been established yet, but we know that RS cell activation is a prerequisite for movement production. The activity of these cells constitutes an excellent monitor for motor activation in lampreys. We took advantage of this and developed a preparation in which the brain and rostral spinal cord were isolated in vitro, along with an intact olfactory epithelium (see the Materials and Methods section). We applied physiological and anatomical tools to examine the neural substrate of olfactory-motor responses in this preparation, which provides excellent accessibility to all potential relays carrying olfactory inputs to motor command neurons in the brainstem. To confirm the locomotor role of potential relay areas of olfactory inputs, we used a semi-intact preparation, with the tail left attached to monitor swimming behavior.

\section{Results}

\section{Activation of RS Neurons by Olfactory Inputs}

We used an isolated brain-spinal cord preparation, with an intact olfactory epithelium, to examine the effect of odor on the responses of RS cells recorded intracellularly. We found that odor stimulation of the olfactory sensory neurons induced large excitatory responses in RS cells. Lamprey pheromones have already been demonstrated to attract adult lampreys and generate locomotion in their natural surroundings $[4,9]$. Application of the

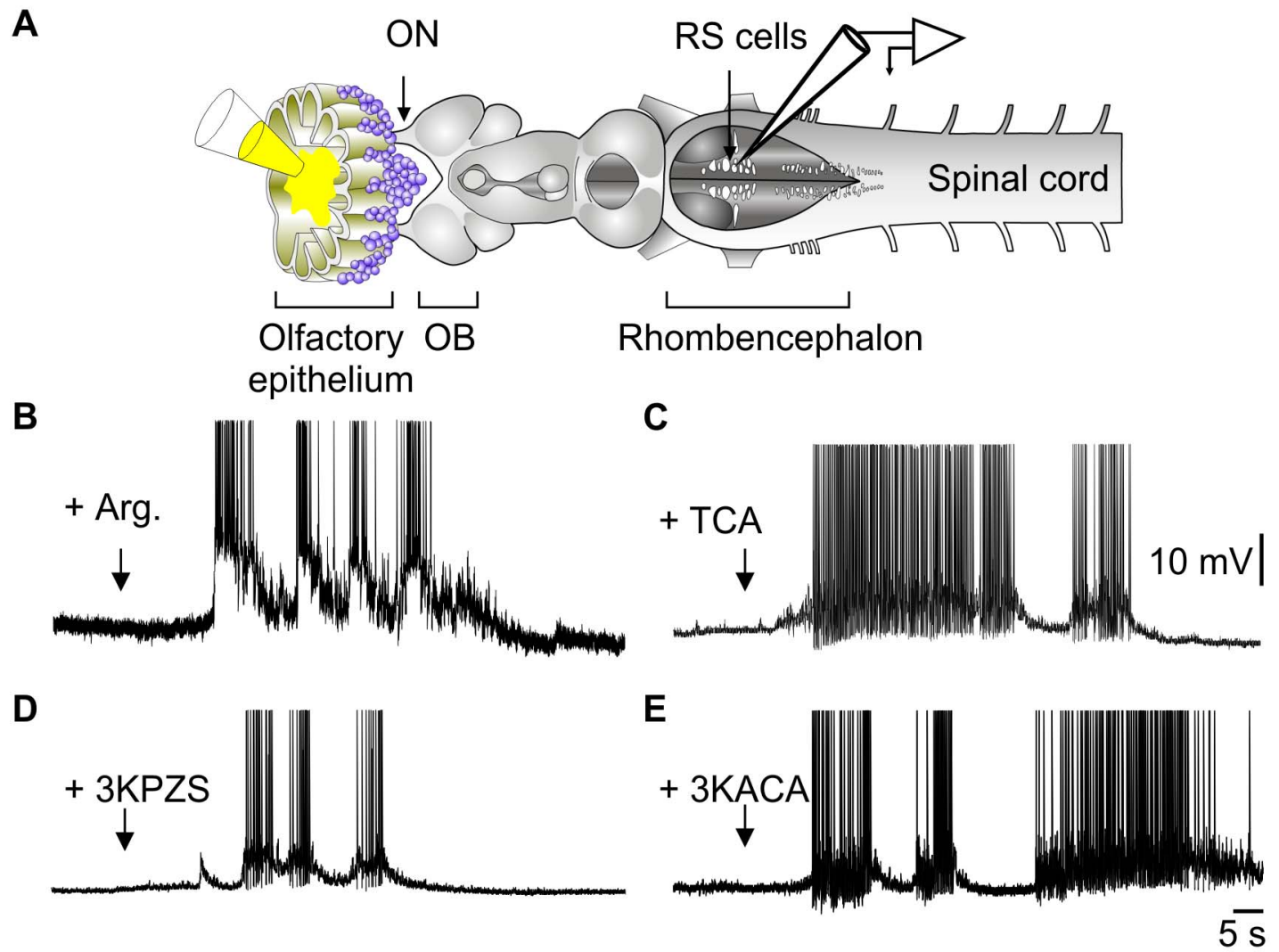

Figure 1. Olfactory epithelium stimulation activates RS cells. (A) Illustration of the experimental procedure in an isolated olfactory epithelium-brain-spinal cord preparation. (B) Responses of RS cell to the application of L-arginine over the olfactory epithelium (Arg, $1 \mathrm{mM}$ ). (C) Response to bile acid-taurocholic acid (TCA, $1 \mu \mathrm{M})$. (D-E) Responses to male-secreted pheromones, 3-keto-petromyzonol sulfate (3KPZS, $10 \mu \mathrm{M})$, and 3-keto allocholic acid (3KACA, $10 \mu \mathrm{M})$, respectively. Arrows represent the onset of odor ejection. (B-E) are from different preparations. doi:10.1371/journal.pbio.1000567.g001 
odor molecules L-arginine ( $1 \mathrm{mM}, n=11$, Figure $1 \mathrm{~B})$, the bile acid-taurocholic acid $(1 \mu \mathrm{M}, n=3$, Figure $1 \mathrm{C})$, or the malesecreted pheromones 3-keto petromyzonol sulfate (3KPZS; $10 \mu \mathrm{M}, n=3$, Figure 1D) and 3-keto allocholic acid (3KACA, $10 \mu \mathrm{M}, n=3$, Figure 1E) onto the olfactory epithelium using a Picospritzer injection system induced large sustained depolarizations with spiking activity in RS cells. The excitatory responses occurred on average $35.7 \pm 6 \mathrm{~s}$ after the application, with similar latencies for all olfactory substances. These long latencies likely reflected the time needed for the odor molecules to diffuse into the lumen of the peripheral olfactory organ and reach olfactory sensory neurons. Excitatory responses to odors and pheromones were observed in RS cells of both females and males. Application of the Ringer's carrier solution failed to elicit responses. It is noteworthy that often we did not get any response in preparations from these wild-caught animals, when kept in captivity for a long period of time. Desensitization of the olfactory sensory neurons or a modulatory depression within the pathway could have occurred, and further experiments are needed to clarify this question.

To investigate the physiological pathway involved, we first established whether RS cells responded to electrical stimulation of the olfactory nerve $(\mathrm{ON})$. We stimulated the $\mathrm{ON}$ unilaterally and recorded synaptic responses in RS cells intracellularly (Figure 2A). The RS cells on both sides displayed excitatory responses, with a latency of $95 \pm 10 \mathrm{~ms}$ at the ipsilateral $(n=101)$ and $118 \pm 13 \mathrm{~ms}$ at the contralateral side $(n=44$, not statistically different, MannWhitney test, $p=0.88$ ). The constant latency with repeated stimulation and the sharp onset of the RS cell responses suggested a strong link between olfactory sensory areas and locomotor command neurons. Temporal summation was also observed when using trains of stimuli (Figure 2A), suggesting at least a few synapses along this pathway. Similar responses were seen from larvae, newly transformed, parasitic, and spawning animals (thus at different ages), suggesting the presence of anatomical connections between the olfactory and motor systems throughout the lamprey life cycle. Because the lamprey brainstem contains about 2,500 RS neurons, and intracellular recordings allow the sampling of a relatively limited number of them, we performed calcium imaging experiments to determine whether olfactory inputs also activated populations of RS cells. Repetitive stimulation of the ON $(10-100 \mu \mathrm{A}, 10 \mathrm{~Hz}, 2-10 \mathrm{~s})$ elicited a large rise in intracellular calcium in many RS cells in the middle rhombencephalic reticular nucleus (MRRN) on both sides, in the six preparations examined (Figure 2B). The calcium responses lasted tens of seconds, which has been associated with lasting afterdischarges in RS cells [17].

Perfusion of glutamate receptor antagonists (AP5: $100 \mu \mathrm{M}$, CNQX: $10 \mu \mathrm{M}, n=3$ ) into the recording chamber blocked the response of RS cells to ON stimulation (Figure 2G). In addition, local injections of these antagonists into the OB (AP5: $10 \mathrm{mM}$, CNQX: $1 \mathrm{mM}, n=6$, Figure 2D) had the same effect, indicating that olfactory primary afferent inputs in the OB rely on glutamate neurotransmission. To determine whether the powerful excitation of RS cells produced by olfactory inputs was associated with locomotion, suction electrodes were positioned over the ventral
A
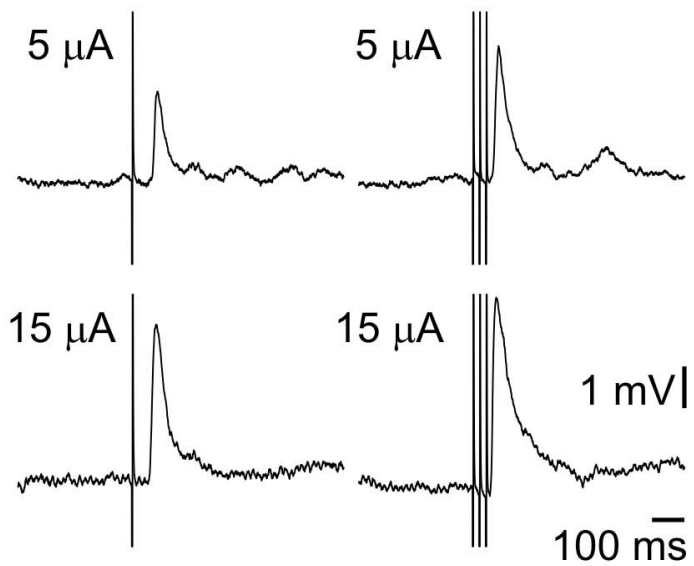

C Bath application

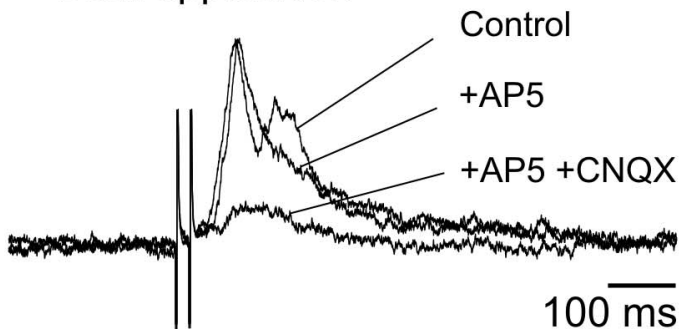

B
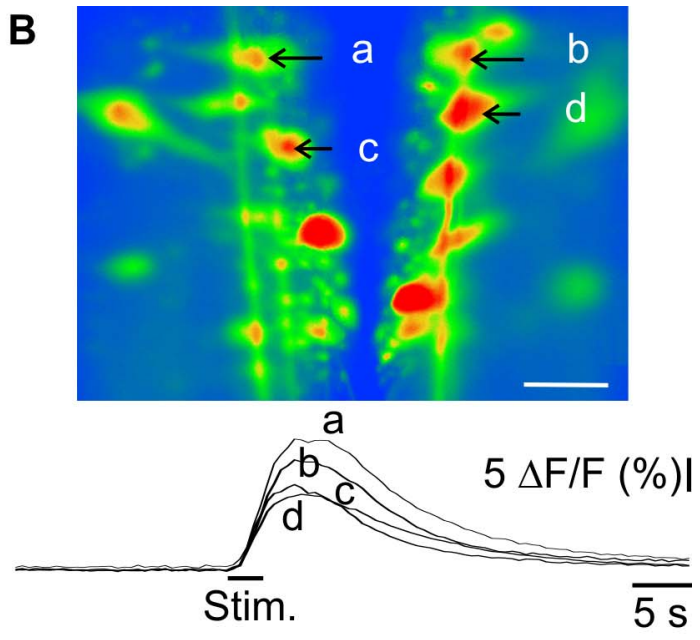

Local injection

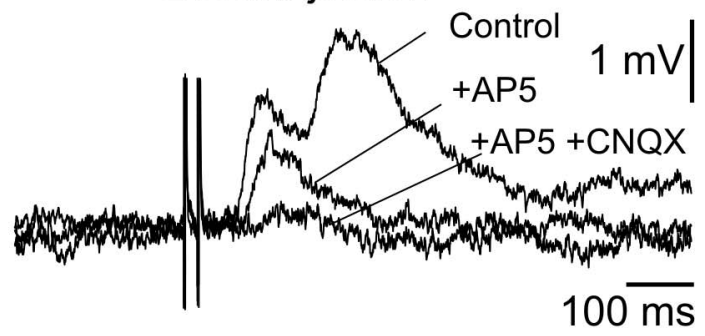

Figure 2. Olfactory nerve stimulation activates RS cells. (A) Responses of RS cells following electrical stimulation of the ON with 5 or $15 \mu \mathrm{A}$ (top versus bottom traces); single shocks or trains of stimulation (left versus right traces). Each trace is a mean of eight individual responses. (B) Calcium fluorescence imaging illustrates the $\Delta \mathrm{F} / \mathrm{F}$ response of identified RS cells to ON stimulation $(20 \mu \mathrm{A}-10 \mathrm{~Hz})$. (a, c) ipsilateral. (b, d) contralateral. White scale bar in the photomicrograph represents $100 \mu \mathrm{m}$. (C) RS responses to ON electrical stimulation are reduced by glutamate antagonists perfused through the bath $(50 \mu \mathrm{A}$ stimulation, upper traces) (D) or injected onto the $\mathrm{OB}(50 \mu \mathrm{A}$ stimulation, bottom traces). doi:10.1371/journal.pbio.1000567.g002 
A
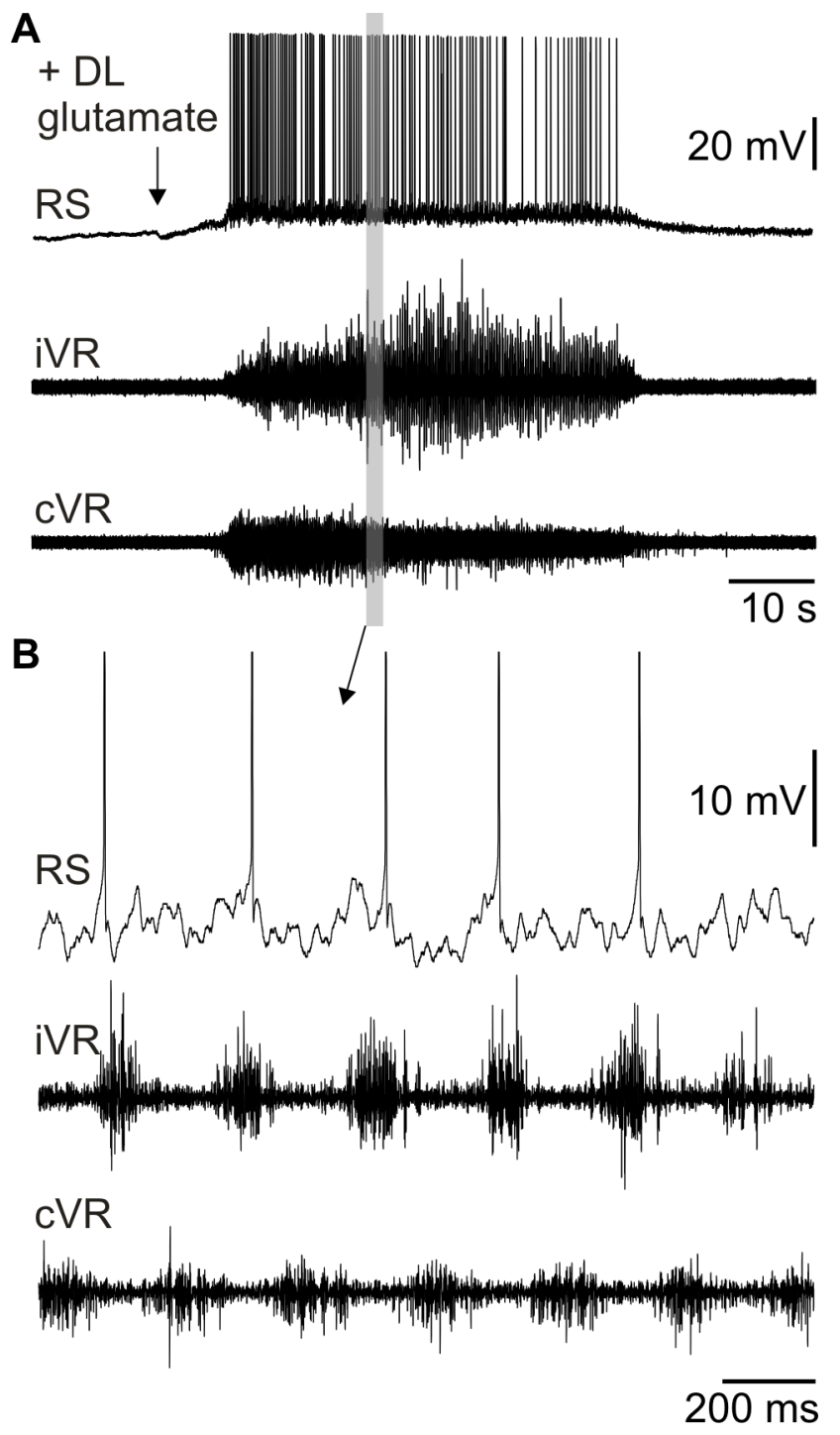

Figure 3. Glutamate injection into the $O B$ induces fictive locomotion. (A) Top trace: Intracellular recording of a RS cell. Note the large excitation induced by the injection of $3 \mathrm{mM}$ glutamate in the ipsilateral OB. Bottom traces: Ventral root (VR) discharges on both sides. (B) Detail from the boxed area in (B) shows fictive locomotion characterized by alternating ipsilateral and contralateral ventral root activity (iVR and cVR, respectively). Note that the RS cell shows rhythmic oscillations in tune with the fictive locomotor pattern.

doi:10.1371/journal.pbio.1000567.g003

roots to record the motor output generated by spinal cord networks. A unilateral local application of glutamate $(3 \mathrm{mM}, n=4)$ in the OB induced large sustained depolarizations with superimposed action potentials in RS cells, while rhythmic bursts of activity alternated bilaterally in the ventral roots (Figure $3 \mathrm{~A}-\mathrm{B}$ ). This type of motor activity is referred to as "fictive locomotion" [23-25]. Taken together, these experiments suggested a strong link between olfactory inputs and the neural control circuitry for locomotion.

\section{Localization of an OB Relay}

We then carried out experiments to physiologically identify the neural connectivity linking the olfactory input to locomotor centers. We first examined whether all $\mathrm{OB}$ regions transmitted

A

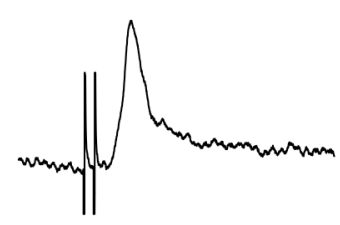

C
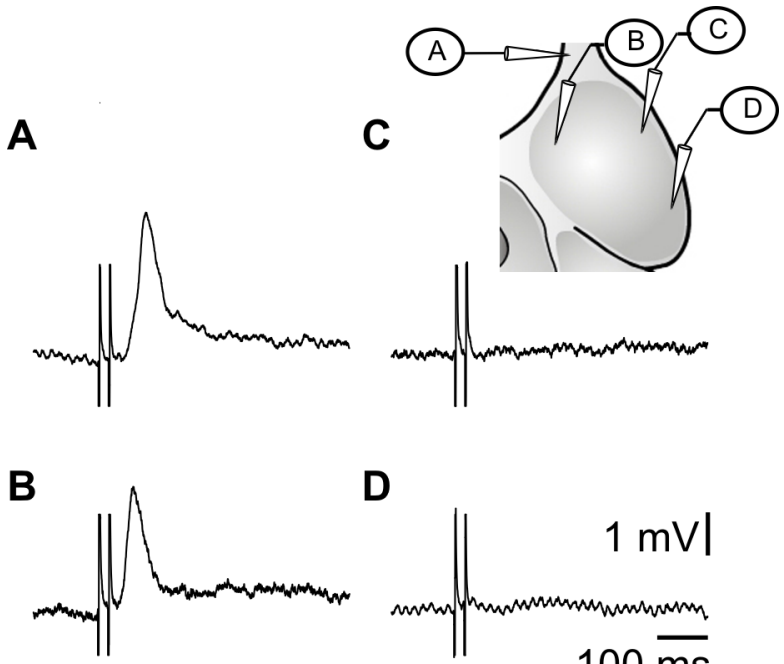

$\mathbf{E}$

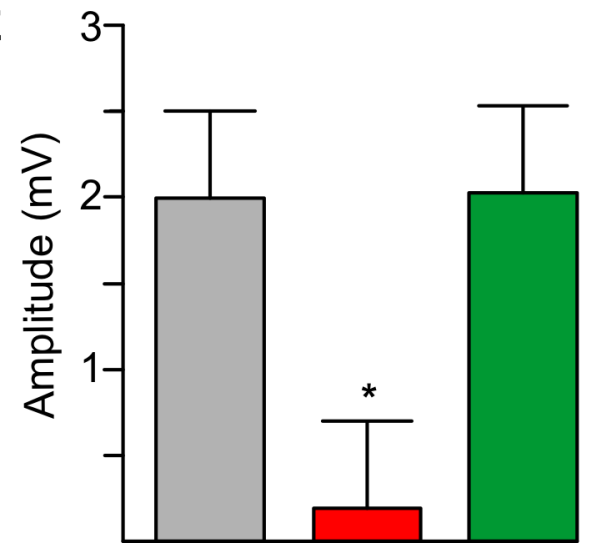

Figure 4. Olfactory-locomotor information transits through the medial region of the OB. (A-D) Responses in a single ipsilateral RS neuron to $30 \mu \mathrm{A}$ stimulation of the $\mathrm{ON}$ and $\mathrm{OB}$. The schematic (inset) indicates the location of stimulating electrodes. Note that a synaptic response was elicited only following stimulation of the ON or the medial part of the OB. (E) Mean amplitude of 4 RS cells responses to $30 \mu \mathrm{A}$ ON stimulation before (grey bar) and after local injection of AP5 and $\mathrm{CNQX}$ mixture in the central-medial $\mathrm{OB}$ (red bar) and lateral $\mathrm{OB}$ (green bar). * $p<0.05$.

doi:10.1371/journal.pbio.1000567.g004

olfactory inputs to RS cells, by comparing RS responses to ON stimulation, to those elicited by stimulating different parts of the OB (Figure 4A-D). Stimulating the medial part of the OB $(30 \mu \mathrm{A})$ elicited excitatory synaptic responses in RS cells with a mean response amplitude of $2.1 \pm 0.3 \mathrm{mV}(n=13$ animals, Figure 4B). Overall, RS responses to ipsilateral medial OB stimulation occurred with a mean latency of $71 \pm 7 \mathrm{~ms}(n=39)$. Responses to $30 \mu \mathrm{A}$ stimulation of the lateral portion of $\mathrm{OB}$ were much smaller $(0.6 \pm 0.2 \mathrm{mV}$, paired $t$ test, $p<0.001$ ) and often absent (Figure 4C, D). The threshold intensity needed for eliciting excitatory responses in RS cells was compared for stimulation of the ON and different parts of OB (not shown). Stimulating the ON or the medial part of the OB elicited RS responses with a similar mean threshold intensity of $4.2 \pm 1 \mu \mathrm{A}$ and $12.4 \pm 5 \mu \mathrm{A}$, respectively (paired $t$ test, $p=0.197 ; n=5$ ), whereas stimulation anywhere else in the $\mathrm{OB}$ required much stronger stimulation intensities. We tested stimulation intensities up to $50 \mu \mathrm{A}$ in non-medial $\mathrm{OB}$ locations and RS responses were often absent. If responses were present, they never exceeded $1 \mathrm{mV}$ in amplitude. The above 
results were confirmed by locally injecting glutamate receptor antagonists into the OB (AP5: $10 \mathrm{mM}$, CNQX: $1 \mathrm{mM}$ ). Only injections into the medial territories reduced the RS responses to ON stimulation $(n=4$, Figure $4 \mathrm{E})$. In addition, local injections of glutamate $(3 \mathrm{mM})$ within the medial $\mathrm{OB}$ induced ventral root discharges, whereas injections in other parts had no effect $(n=3$, not shown). RS synaptic responses to ON stimulation were not affected by surgical ablation of the lateral portion of the OB $(n=4$, not shown). Altogether, these experiments indicate that the medial part of the OB is crucial for eliciting excitatory responses in RS cells.

\section{Neural Pathway Involved in Olfactory-Locomotor} Transformations

Anatomical experiments were then carried out to determine whether the projections from the medial part of the OB differed from the rest of the OB. The lateral OB was injected with Texas Red-conjugated dextran amines $(n=10$, Figure 5A) and anterograde labeling confirmed projections to the lateral pallium [11]. When the tracer was injected in the medial OB $(n=15$, Figure $5 \mathrm{~A}$, B), labeled fibers were found descending bilaterally to a caudal ventral region of the diencephalon, the posterior tuberculum (PT). This region was previously shown to project to the MLR in

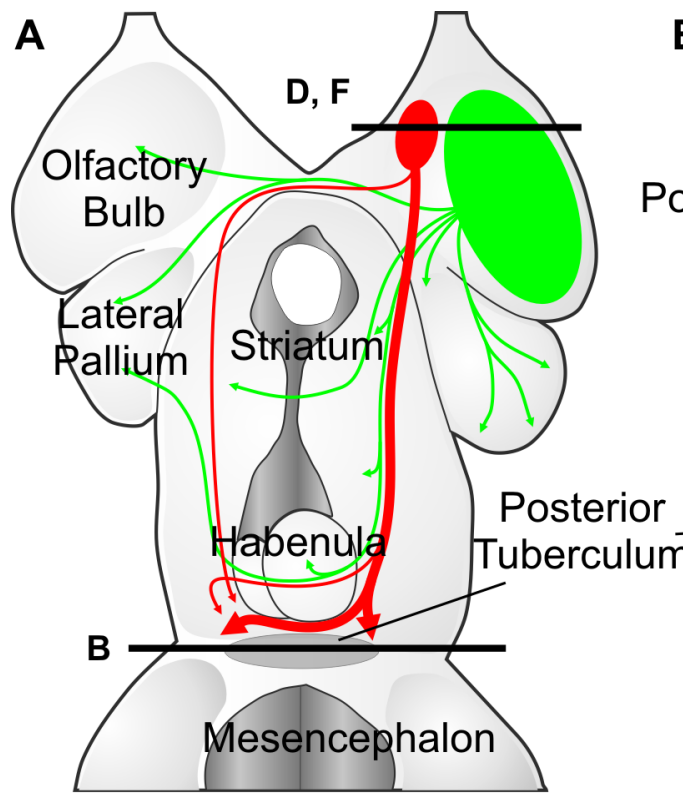

B

C

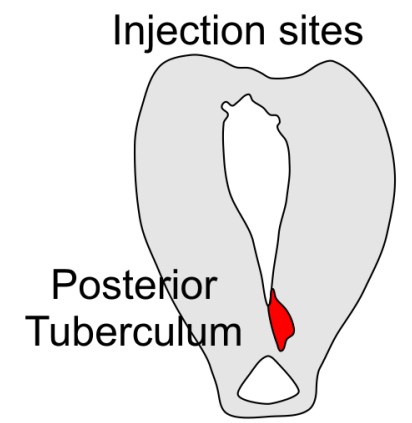

$\mathbf{E}$

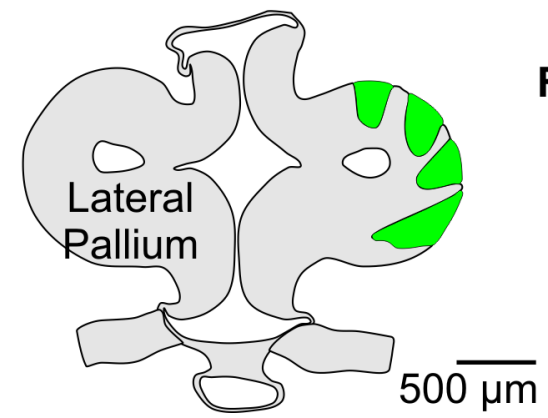

D

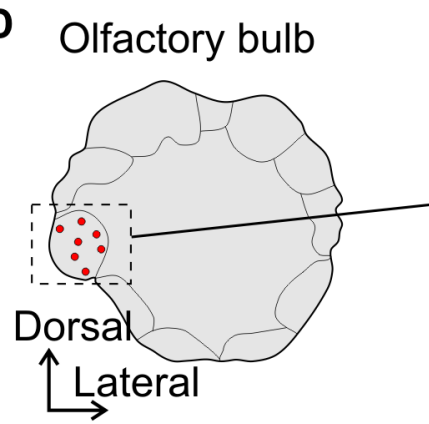

$\mathbf{F}$

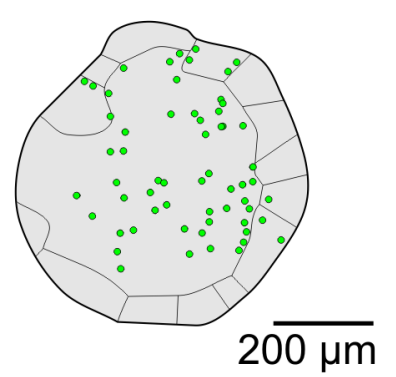

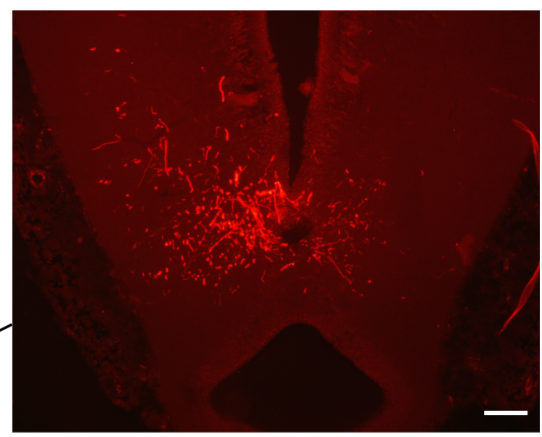

$500 \overline{\mu \mathrm{m}}$
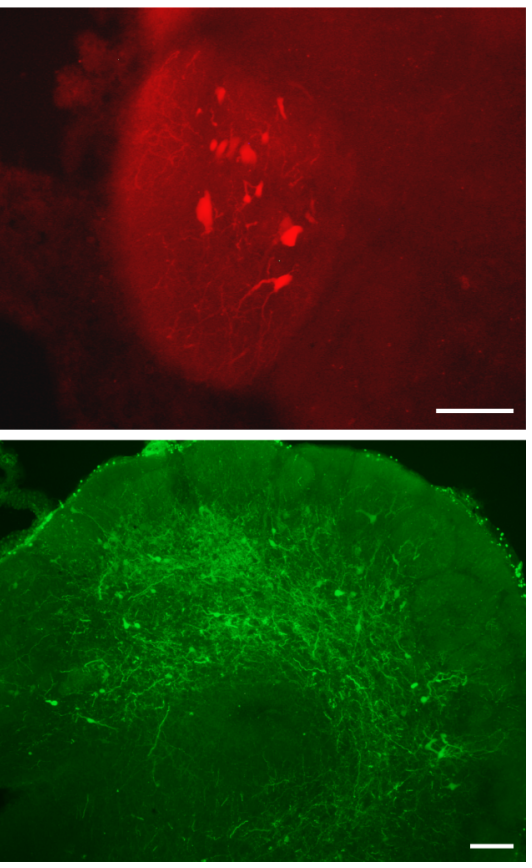

Figure 5. The medial region of the OB projects to the PT. (A) Schematic dorsal view of the forebrain summarizing the efferent OB projections in the lamprey. Projections from OB regions other than the medial region are shown in green. (B) Anterograde labeling from the medial OB (red) shows fibers terminating in the PT (see picture to the right). (C, D) Retrograde labeling from the PT shows neuronal cell bodies in only one medial glomerulus in the $\mathrm{OB}$ (see picture to the right). (E, F) Retrograde labeling from the lateral pallium shows neurons associated with almost all glomeruli, except the medial. White scale bars in pictures represent $100 \mu \mathrm{m}$.

doi:10.1371/journal.pbio.1000567.g005 
lampreys [26]. We then carried out retrograde tracing experiments. Dorsal, lateral, and ventral injections into the lateral pallium (Figure 5A, E) labeled mitral-like cells throughout the dorsal $(n=7)$, lateral $(n=5)$, and ventral $(n=3)$ parts of the OB, respectively. No labeling was found in the medial $\mathrm{OB}$ region (Figure $5 \mathrm{~F}$ ). Interestingly, the $\mathrm{OB}$ labeling pattern following injection into the PT was altogether very different (Figure 5A, C, D). Retrogradely labeled neurons were found only in a medial $\mathrm{OB}$ glomerulus on both sides of the brain $(n=5$, Figure $5 \mathrm{C}, \mathrm{D})$. The axonal projections were also examined anatomically. Two separate bundles left the $\mathrm{OB}$ - one coursed dorsally under the dorsomedial telencephalic neuropil and the other ventromedially through the septal and preoptic area. These two bundles merged into a single diffuse tract at the level of the caudal part of the dorsal pallium, extended caudally through the thalamus and hypothalamus, and terminated in the PT, where some fibers crossed the midline (see Figure 5A). These results indicated that there is a distinct projection from the medial part of the OB to the caudal ventral diencephalon that could elicit excitatory responses in RS cells and locomotor activity in response to glutamatergic excitation of the $\mathrm{OB}$.

We then tested the effects of stimulating the PT on RS cell activity. Single shocks $(1-10 \mu \mathrm{A})$ elicited EPSPs in all of the RS cells tested in 12 lampreys, with a mean latency of $14 \pm 2 \mathrm{~ms}$ (Figure 6A). Temporal summation occurred when using trains of stimuli $(5 \mathrm{~Hz})$. In a semi-intact preparation (with the tail kept intact swimming freely in the recording chamber, Figure 6B), local injections of $3 \mathrm{mM}$ glutamate into the PT induced swimming movements $(n=3$, Figure 6C, D). In addition, injections of glutamate antagonists into the PT blocked the response of RS cells to ON stimulation in the isolated brain preparation $(n=6$, Figure $7 \mathrm{~A}, \mathrm{~B})$. This indicates that the transmission from the medial part of the $\mathrm{OB}$ to the PT is glutamatergic and that the $\mathrm{PT}$ is indeed a key player in relaying $\mathrm{OB}$ inputs to locomotor centers. Because PT neurons project to the MLR [26], which in turn sends powerful inputs to RS cells [19], we investigated whether the MLR acted as an olfactory relay to RS cells. Local injections of glutamate antagonists into the MLR markedly reduced the RS response to stimulation of the ON (5$30 \mu \mathrm{A} ; n=5$, Figure 7A, C), suggesting that the MLR is involved in transmitting olfactory inputs to RS cells.

RS cells also receive projections from the DLR [22]. This region also receives inputs from the $\mathrm{OB}$ and is located slightly rostral and dorsal to the PT $[22,27]$. A local injection of glutamate antagonists in the DLR did not block RS responses $(n=4$, Figure 7A, D) to 5$30 \mu \mathrm{A}$ stimulation of the ON, suggesting that DLR is not a relay in the olfactory-locomotor pathway.

\section{Discussion}

Sensorimotor transformations have been described in different models including lampreys [28-31]. Results from this study are the

A
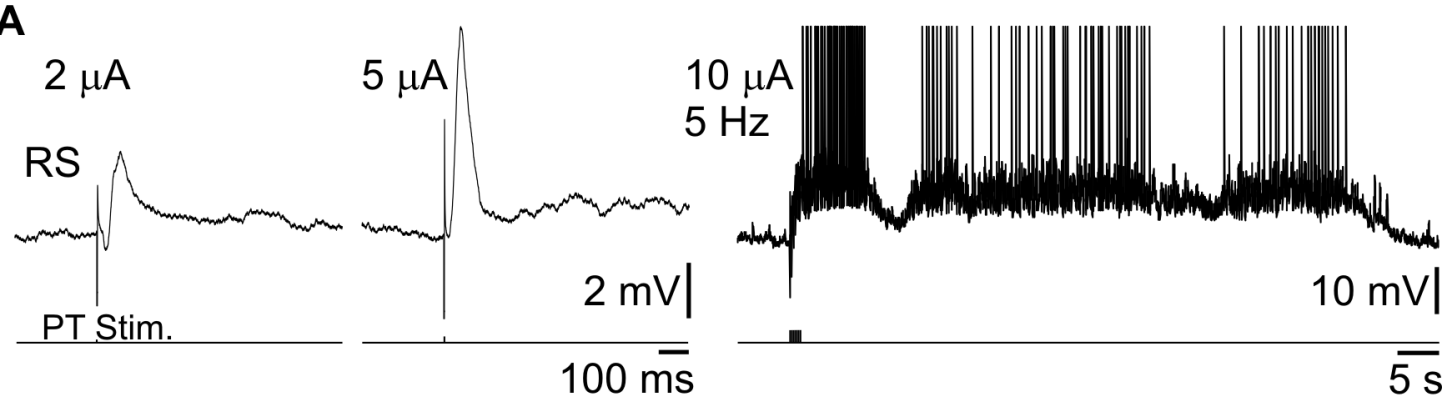

B

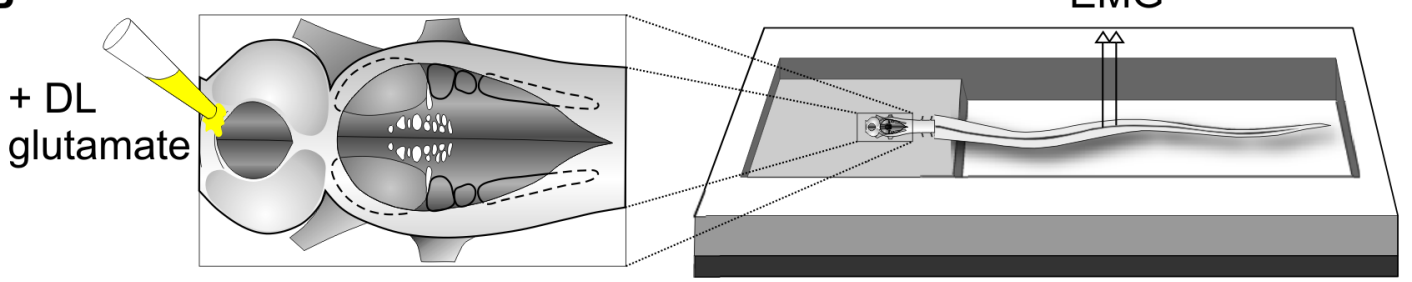

\section{C + DL Glutamate}

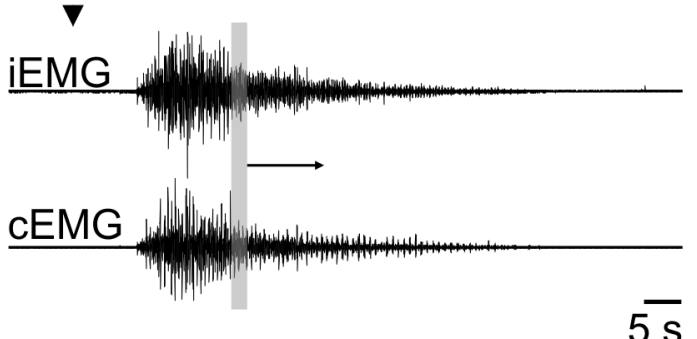

D
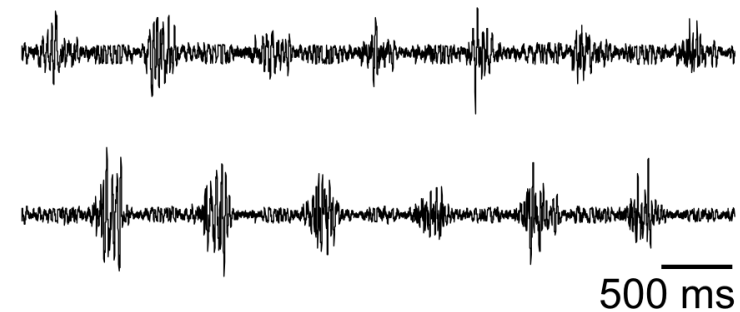

Figure 6. Stimulation of the PT activates RS neurons and locomotion. (A) PT stimulation induces RS responses. Raising the stimulation intensity from 2 to $5 \mu \mathrm{A}$ increases the amplitude of the evoked synaptic responses (left two traces), while a short stimulation train $(10 \mu \mathrm{A}-5 \mathrm{~Hz}$ ) elicited a long-lasting afterdischarge in the same RS cell (right trace). (B) Illustration of the semi-intact preparation. (C) Glutamate (3 mM) injected into the PT elicited swimming and bursts of activity on EMG recordings. iEMG, ipsilateral; CEMG, contralateral. (D) Enlargement of the boxed area in (C) shows left and right muscle contractions.

doi:10.1371/journal.pbio.1000567.g006 
A

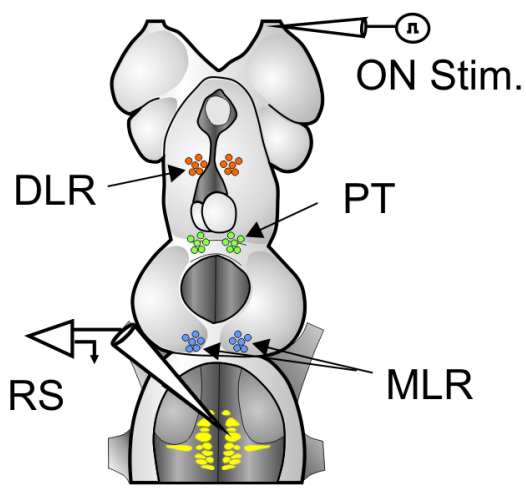

B

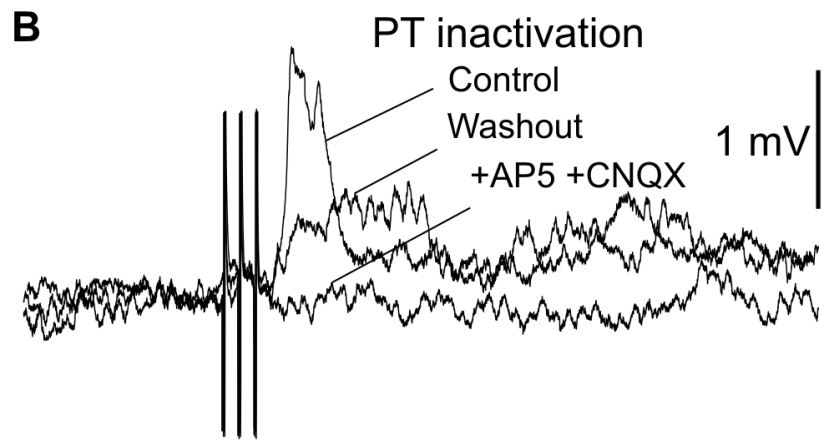

C

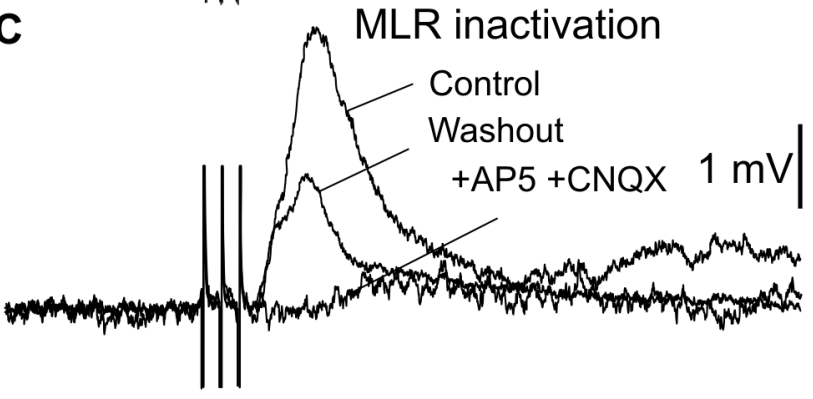

D

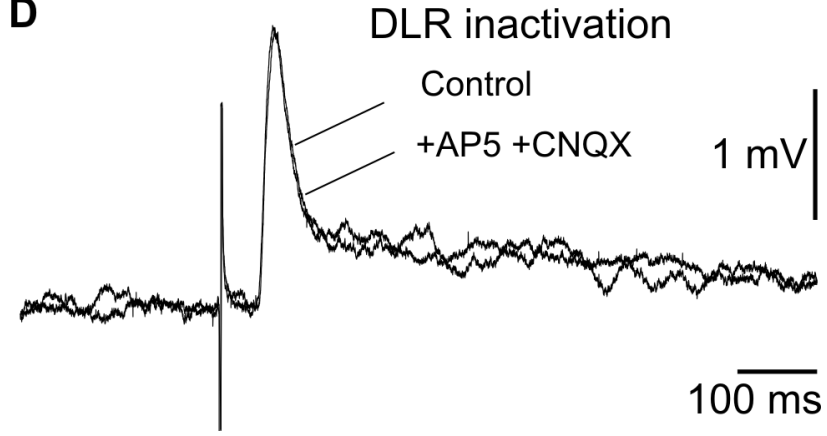

Figure 7. Olfactory inputs are relayed via the PT and MLR. (A) Schematic illustration showing the experimental procedure where glutamate receptor antagonists were injected in different sites indicated by the arrows. (B) RS cell responses to ON stimulation are strongly decreased by the injection in the PT. (C) Injection in the MLR has a similar effect. (D) An injection in the DLR does not block the synaptic responses. (B, C, D) are from different preparations. doi:10.1371/journal.pbio.1000567.g007

first description, to our knowledge, of the neural substrate underlying the transformation of olfactory inputs into a motor output in a vertebrate. This newly identified pathway originates from the medial $\mathrm{OB}$ and projects to the PT in the caudal diencephalon. From there, a projection to the MLR sends powerful inputs to RS cells [19] and activates spinal locomotor networks (see Figure 8). This new description of neural processing of olfactory inputs suggests that the vertebrate olfactory system could be organized in functional clusters, with a motor cluster originating from the medial OB. Interestingly, an olfactory pathway dedicated to reproduction was previously described in mammals [32]. In lampreys, there could also be other clusters related to reproduction or feeding, for example.

\section{Neural Substrate for the Transformation of Olfactory Inputs into Locomotion}

We were able to chemically stimulate olfactory sensory neurons with naturally occurring, biologically relevant odors in a reduced in vitro preparation, and generate large excitatory responses in RS cells. These responses were elicited by different classes of odors involved in reproduction and feeding behaviors. While odorant diffusion into the nasal cavity likely accounted for RS neuron response latency, we have recently decreased the $\mathrm{OB}$ cell response latency to about $2 \mathrm{~s}$, by applying a perfusion system for rapidly delivering larger volumes of odors within the nasal cavity by using an electronically triggered three-way solenoid valve for fast switching from normal Ringer's solution to a desired odor, without interrupting flow to the olfactory epithelium [33].

We have previously shown that sustained depolarizations in RS cells activate the spinal locomotor networks leading to swimming in lampreys $[17,18]$. Thus, the elicited excitatory activity in RS cells, obtained after chemically activating olfactory sensory neurons, could generate motor activity in intact animals, such as when ovulating female lampreys are attracted by pheromones released by males [4]. In the present context, it was not possible to determine if the motor responses are attractive versus repulsive. The kinematic details of the motor output cannot be determined from ventral root recordings during fictive swimming. Further analyses in intact lampreys will be necessary to examine this.

Measurement of the latency between $\mathrm{ON}$ stimulation and ipsilateral RS responses provides the best indication of transmission velocity within the olfactory-locomotor pathway, as this approach was not dependent on molecular diffusion delays within the nasal cavity. We uncovered a pathway with a few synapses from the ON to RS cells. Disynaptic sensory inputs to lamprey RS cells have been well established in the past from the spinal dorsal columns [34], as well as trigeminal [35] and vestibular [36] afferents. These synaptic responses were very similar to those described here for olfactory inputs, except that we now show that four synapses are present in the olfactory-reticular pathway. As such, the first olfactory relay, the $\mathrm{OB}$, does not project directly to RS cells as in other sensory systems [34-36], but its most caudal target is the PT [37]. In turn, RS cells do not receive inputs from structures more rostral than the diencephalon $[22,38]$.

The physiological and anatomical data also suggest that the medial part of the $\mathrm{OB}$ is necessary for eliciting motor activity in response to olfactory stimulation. Synaptic responses in RS neurons were observed only when this medial OB region was stimulated, and axons projected prominently from this site to the PT - a region with abundant dopaminergic neurons, and proposed by some to be equivalent to the ventral tegmental area of mammals [39]. We have shown that this olfactory-locomotor transformation also involves the MLR, a region with a central role in initiating and controlling locomotion [18,19,40]. MLR control of the power of locomotor output [18] may fine-tune swimming elicited by olfactory stimulation. While blocking the DLR did not alter the responses to olfactory inputs, the physiological context involving DLR activation remains unknown. It may have modulatory effects on olfactory-locomotor pathway under specific 


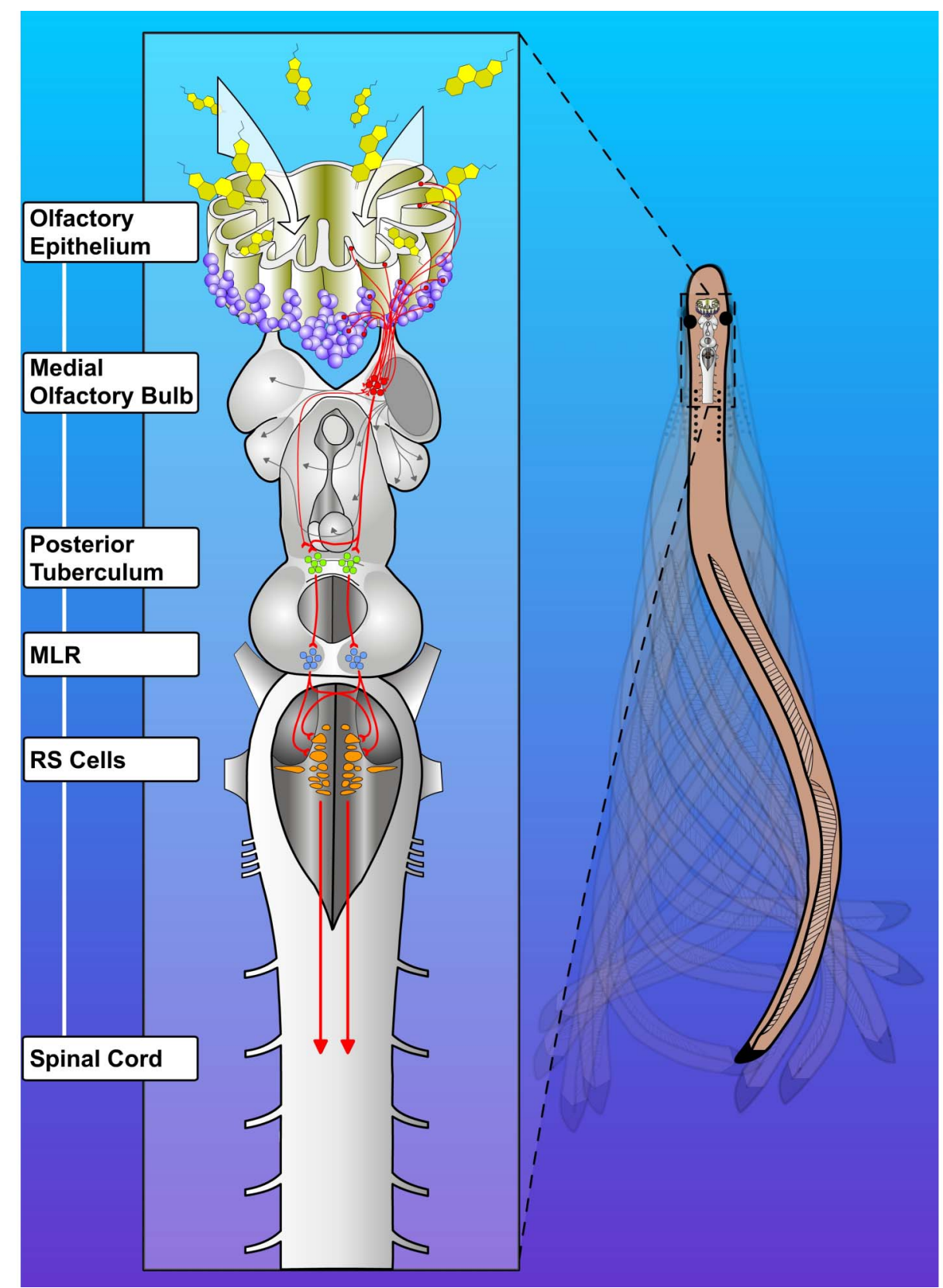

Figure 8. Schematic representation of the olfactory-locomotor circuitry in lampreys. Stimulation of the olfactory sensory neurons in the periphery activates neurons in the $\mathrm{OB}$. There are two distinct projections from the $\mathrm{OB}$, one from the lateral and another from the medial part. The lateral part projects to forebrain structures including the lateral pallium, the striatum with some fibers reaching down to habenula (grey arrows). The medial part is the relevant part for generating locomotor behavior. There is a direct projection from the medial part of the OB to the PT. From the PT, there is a projection to the MLR, known to play a crucial role in controlling locomotion in all vertebrate species. MLR neurons project to brainstem reticulospinal neurons, acting as command cells for locomotion. RS cells, in turn, project directly to spinal cord neurons that generate the basic muscle synergies responsible for propulsion during locomotion. doi:10.1371/journal.pbio.1000567.g008

conditions, without directly transmitting olfactory inputs to RS cells.

\section{Are There Two Separate Olfactory Systems in Lampreys?}

Although the organization of main olfactory epithelium and the accessory olfactory organ is not fully understood yet, recent anatomical data indicate that the accessory olfactory organ neurons project exclusively to the medial OB [11], whereas those in the main olfactory epithelium project to the entire OB.
We found that canonical odorant molecules such as arginine or bile acids evoked RS cell responses very similar to those obtained with sex pheromones, and the neural pathway for the olfactory-locomotor transformation is likely to be the same in both cases. Our observations also suggest that the accessory olfactory organ only activated the locomotor pathway through the medial $\mathrm{OB}$, since it does not project to more lateral OB regions. It remains to be determined whether the lateral $\mathrm{OB}$ receives peripheral pheromone inputs from the main olfactory 
epithelium. Recent observation of both odor and pheromone activation of the main and accessory $\mathrm{OB}$ in mice [41] has also prompted reevaluation of the classical functional separation of the olfactory system into two subsystems, with the main olfactory system responding to "odors" and the vomeronasal system responding to "pheromones."

Our work on lampreys supports the hypothesis that the distinction between two olfactory subsystems may rely on functional output projections rather than on the olfactory molecules that first act on the system. Both anatomy and physiology show that only medial $\mathrm{OB}$ output neurons project to the PT, whereas other parts of the OB project to the lateral pallium. We also know that olfactory sensory neurons in both main and accessory regions of the peripheral olfactory organ project to the medial OB [11]. This suggests that the medial OB might be involved in generating motor behavior and take part in an olfactory-locomotor pathway irrespective of the type of odor molecules that are eliciting the responses. This pathway may be equally involved in food-seeking and mate-finding. The localization of olfactory transduction proteins also suggests a specific role for the medial region of the OB. The axons of olfactory sensory neurons in the medial glomerulus are not immuno-reactive to $G_{\text {olf }}$, a cAMP-dependent olfactory $G$ protein [12], whereas $G_{\text {olf }}$ is localized in neurons projecting to all other parts of the OB. Accumulating evidence points to two distinct olfactory pathways in lampreys, one for specific odor detection and discrimination, and the other, the medial OB-PT pathway described here, for generating motor behavior in response to many different types of odorants.

This olfactory-locomotor transformation, through a specific pathway comprised of only a few relays in the brain, may be important for strongly linking movement responses to olfactory cues and for quickly producing motor behaviors in response to odors and pheromones. A direct projection from the $\mathrm{OB}$ to the diencephalon has been described in other species including fishes $[38,42,43]$, amphibians [44], and mammals [45-47]. For instance, previous studies have reported OB projections to the PT $[42,43]$, the hypothalamus [45-47], and the habenula [44,48]. In these vertebrates, such projections may also be important for rapid motor behaviors in response to olfactory inputs. In reptiles and mammals, the accessory OB projects to the amygdala before reaching any diencephalic region such as the hypothalamus, where these inputs likely modulate endocrine function [49]. It is noteworthy that a direct projection from the accessory $\mathrm{OB}$ to the hypothalamus was also seen in mammals [45]. This is particularly important with regards to the role of the hypothalamus in activating locomotion [50]. Indeed, there are several regions of the hypothalamus projecting to the MLR, and their stimulation induces stepping in mammals [50]. However, the link between olfactory inputs and locomotor responses has not been fully investigated in mammals, although locomotor behavior tightly tied to input from the olfactory system is both commonplace and remarkable. Olfactory inputs powerfully activated stepping movements in newborn rats at an early developmental stage preceding free-will locomotion [2], and locomotor responses to olfactory cues, including nipple search behavior in neonatal rabbits [51] and tracking behavior in dogs [52], were also described. In particular, recent discovery that the vomeronasal organ is directly responsible for male behavior, including vocalization, and movements associated with aggression and sexual activity in mice [53], may mean that mammals have conserved aspects of the olfactory-locomotor pathway that has been described in the present study. There could be common features as well as distinctions in olfactory-locomotor pathways in different vertebrate species. For instance, in the zebrafish, it is the lateral part of the $\mathrm{OB}$ that is responsible for the behavioral attraction to amino acids [54].

In conclusion, results from the present study indicate that the stimulation of the olfactory system activates the motor command system in lampreys. Locomotion is triggered by a glutamatergic pathway originating from the medial $\mathrm{OB}$ and projecting first to the PT, then to the MLR, before reaching RS neurons. The clear effects of physiologically blocking excitatory glutamatergic transmission to neurons in the different relays of the pathway indicate that this pathway constitutes a major component for transforming olfactory inputs into motor output. Lampreys are considered amongst the most ancestral extant vertebrate species. The conservation of such a pathway during vertebrate evolution could constitute the neural basis underlying motor responses elicited by olfactory inputs in higher vertebrates as well [2].

\section{Materials and Methods}

\section{Ethics Statement}

All surgical and experimental procedures conformed to the guidelines of the Canadian Council on Animal Care (CCAC) and were approved by the Université de Montréal and Université du Québec à Montréal animal care committees, and the University of Windsor animal care committee, where some of the anatomical experiments were performed.

\section{Animal Preparation}

Experiments were performed on 98 reproductive adult sea lampreys (Petromyzon marinus) of both sexes provided by the Great Lakes Fishery Commission and the Department of Fisheries and Oceans Canada. In addition, some of the electrophysiology studies were carried out on larval $(n=62)$, newly transformed $(n=102)$, and parasitic $(n=7)$ lampreys. All animals were kept in aerated fresh water maintained at $7^{\circ} \mathrm{C}$ until used.

\section{Electrophysiology}

For the GNS attached to the intact olfactory epithelium preparation, the animals were anesthetized with tricaine methanesulphonate (MS-222, $100 \mathrm{mg} / \mathrm{l}$, Sigma-Aldrich, Oakville, ON, Canada) and decapitated at the level of the $7^{\text {th }}$ branchiopore. The surgery and all experiments were performed in cold oxygenated Ringer's $\left(8-10^{\circ} \mathrm{C}\right)$ of the following composition (in $\mathrm{mM}$ ): 130 $\mathrm{NaCl}, 2.1 \mathrm{KCl}, 2.6 \mathrm{CaCl}_{2}$, $1.8 \mathrm{MgCl}_{2}$, 4.0 HEPES, 4.0 dextrose, and $1.0 \mathrm{NaHCO}_{3}$, at $\mathrm{pH}$ 7.4. The branchial apparatus and the myotomal musculature were removed, with all the soft tissue attached to the ventral side of the cranium. A dorsal incision was made to expose the rostral spinal cord and the brain. The nasal cavity was left attached to the brain through the intact ONs. Care was taken to keep a maximum of the olfactory epithelium intact by simply performing a small window opening on its dorsal aspect, to simply permit faster perfusion and washout of odorants.

The preparation was placed into a recording chamber continuously perfused with cold oxygenated Ringer's at a rate of $\sim 4 \mathrm{ml} / \mathrm{min}$. A minimum of $1 \mathrm{~h}$ was allowed for recovery after surgery prior to recording. Using sharp glass microelectrodes filled with $4 \mathrm{M}$ potassium acetate (80-130 M $\Omega$ ), intracellular recordings were made from RS neurons in the MRRN under visual guidance through a binocular microscope (Figure 1A). The signals were amplified with an Axoclamp 2A (Axon Instruments, Foster City, CA). Only RS neurons displaying a stable membrane potential lower than $-70 \mathrm{mV}$ for at least $15 \mathrm{~min}$ were considered in this study. 
For electric stimulations, we used homemade glass-coated tungsten electrodes (4-5 M $\Omega$ with a $10 \mu \mathrm{m}$ tip exposure) and a Grass S88 stimulator (Astro-Med, Longueuil, QC, Canada). Stimulation was applied every $10 \mathrm{~s}$ as single, double, or triple pulses $(2-50 \mu \mathrm{A}$ intensity, $1-2 \mathrm{~ms}$ duration, and $20 \mathrm{~ms}$ pulse interval). Synaptic responses are presented as a mean of eight consecutive responses to the same stimulation.

To observe "fictive locomotion" (Figure 3), we recorded from ventral roots in newly transformed lampreys, using suction electrodes filled with Ringer's solution. The signals were amplified using AM systems 1800 dual channel amplifiers (A-M systems Inc., Sequim, WA).

Semi-intact preparations (Figure 6B-D) were dissected as follows: the brain and rostral spinal cord were exposed like previously described $[17,19]$, whereas the caudal two-third of the body was kept intact to freely swim behind. In this case, because of the presence of cutaneous sensory inputs, the brain was transected at the level of the diencephalon for decerebration purposes before the experiment. The preparation was then transferred into a double compartment recording chamber. Teflon-coated stainless steel microwires (50 $\mu \mathrm{m}$ diameter) were inserted into the segmental muscles for EMG recording.

\section{Calcium Imaging Experiments}

RS cells were retrogradely labeled in Ringer's solution for 24 to $36 \mathrm{~h}$ by placing Calcium-Green dextran crystals (3000 MW, Invitrogen, Eugene, OR) on the rostral stump of the spinal cord, transected at the first segment. Labeled cells were observed on a Nikon epifluorescent microscope equipped with a $20 \times(0.75 \mathrm{NA})$ objective. A fluorescein isothiocyanate (FITC) excitation/emission filter set was used to visualize the neurons. The emitted light was captured with an intensified CCD video camera (Photometrics CoolSNAP HQ Roper Scientific, Tucson, AZ) and recorded at a rate of two images per second, using Metafluor imaging software (Molecular Devices, Sunnyvale, CA). Calcium responses are expressed as relative changes in fluorescence $(\Delta \mathrm{F} / \mathrm{F} \%)$.

\section{Anatomical Experiments}

Anterograde and retrograde labeling was obtained after unilateral injections of Texas Red-conjugated dextran amines (3000 MW, Molecular Probe). A period of 24 to $36 \mathrm{~h}$ was allowed for the transport of the tracer. The preparations were then immersed in a solution of $4 \%$ paraformaldehyde $/ 0.4 \%$ picric acid

\section{References}

1. Selset R, Doving KB (1980) Behaviour of mature anadromous char (Salmo alpinus L.) towards odorants produced by smolts of their own population. Acta Physiol Scand 108: 113-122.

2. Fady JC, Jamon M, Clarac F (1998) Early olfactory-induced rhythmic limb activity in the newborn rat. Brain Res Dev Brain Res 108: 111-123.

3. Varendi H, Porter RH (2001) Breast odour as the only maternal stimulus elicits crawling towards the odour source. Acta Paediatr 90: 372-375.

4. Johnson NS, Yun SS, Thompson HT, Brant CO, Li W (2009) A synthesized pheromone induces upstream movement in female sea lamprey and summons them into traps. Proc Natl Acad Sci U S A 106: 1021-1026.

5. Gray JM, Hill JJ, Bargmann CI (2005) A circuit for navigation in Caenorhabditis elegans. Proc Natl Acad Sci U S A 102: 3184-3191.

6. Kleerekoper H, Mogensen J (1963) Role of olfaction in the orientation of Petromyzon marinus. I. Response to a single amine in the prey's body odor. Physiol Zool 36: 347-360.

7. Applegate VC (1950) Natural history of the sea lamprey (Petromyzon marinus) in Michigan. U S Fish and Wildlife Service Special Scientific Report Fisheries Serv 55: 1-237.

8. Li W, Sorensen PW, Gallaher DD (1995) The olfactory system of migratory adult sea lamprey (Petromyzon marinus) is specifically and acutely sensitive to unique bile acids released by conspecific larvae. J Gen Physiol 105: 569-587.

9. Li W, Scott AP, Siefkes MJ, Yan H, Liu Q et al. (2002) Bile acid secreted by male sea lamprey that acts as a sex pheromone. Science 296: 138-141. in phosphate-buffered saline for 5 to $6 \mathrm{~h}$. They were then transferred overnight into a solution of $20 \%$ sucrose in phosphate buffer. Transverse sections of $25 \mu \mathrm{m}$ thickness were made with a cryostat and mounted on microscope slides with Vectashield (Vector laboratories, Burlington, ON, Canada) for observation under epifluorescence microscopy (Nikon E600 microscope equipped with a DXM1200 digital camera, Nikon, Montreal, QC, Canada; or with a Nikon E800 microscope in Windsor, ON, Canada).

\section{Chemical Stimulations and Drugs}

All drugs were purchased from Sigma-Aldrich (Oakville, ON, Canada), except sex pheromones (graciously provided by Dr. W. $\mathrm{Li}$, Michigan State University, MI). They were kept as frozen concentrated stock solutions (at $-80^{\circ} \mathrm{C}$ for pheromones) and dissolved to their final concentration in Ringer's solution prior to their use. For all local ejections, the inactive dye Fast Green was added to the drug solution to monitor the extent of application. Drug application was performed by pressure ejections of concentrated substances through a glass micropipette in the nasal cavity, or the brain tissue, using a Picospritzer (General Valve, Fairfield, NJ). Ejection of Ringer's with Fast Green at the same location was used as control in each experiment. Chemical stimulations of the olfactory epithelium were performed on reproductive adult lampreys during the first days after their capture in the wild.

\section{Statistics}

Data were analyzed using paired $t$ test or a Mann-Whitney test (Sigmastat, SPSS, Chicago, IL, USA). Significance was set at $p<0.05$. Results are presented as mean \pm S.E.M.

\section{Acknowledgments}

We are grateful to Dr. Weiming Li (Michigan State University) for the lamprey pheromones, Ms. D. Veilleux for technical support, and Mr. F. Bernard for making the illustrations.

\section{Author Contributions}

The author(s) have made the following declarations about their contributions: Conceived and designed the experiments: BZ RD. Performed the experiments: DD AM EA MSP FA SC XR. Analyzed the data: DD AM EA MSP FA SC XR. Wrote the paper: DD BZ RD.

10. Libants S, Carr K, Wu H, Teeter JH, Chung-Davidson YW, et al. (2009) The sea lamprey Petromyzon marinus genome reveals the early origin of several chemosensory receptor families in the vertebrate lineage. B M C Evol Biol 9: 180.

11. Ren X, Chang S, Laframboise A, Green W, Dubuc R, et al. (2009) Projections from the accessory olfactory organ into the medial region of the olfactory bulb in the sea lamprey (Petromyzon marinus): a novel vertebrate sensory structure? J Comp Neurol 516: 105-116.

12. Frontini A, Zaidi AU, Hua H, Wolak TP, Greer CA, et al. (2003) Glomerular territories in the olfactory bulb from the larval stage of the sea lamprey Petromyzon marinus. J Comp Neurol 465: 27-37.

13. Sorensen PW, Fine JM, Dvornikovs V, Jeffrey CS, Shao F, et al. (2005) Mixture of new sulfated steroids functions as a migratory pheromone in the sea lamprey. Nat Chem Biol 1: 324-328.

14. Zielinski BS, Osahan JK, Hara TJ, Hosseini M, Wong E (1996) Nitric oxide synthase in the olfactory mucosa of the larval sea lamprey (Petromyzon marinus). J Comp Neurol 365: 18-26.

15. Zielinski BS, Fredricks K, McDonald R, Zaidi AU (2005) Morphological and electrophysiological examination of olfactory sensory neurons during the early developmental prolarval stage of the sea lamprey Petromyzon marinus L. J Neurocytol 34: 209-216.

16. Northcutt RG, Puzdrowski RL (1988) Projections of the olfactory bulb and nervus terminalis in the silver lamprey. Brain Behav Evol 32: 96-107. 
17. Viana Di Prisco G, Pearlstein E, Robitaille R, Dubuc R (1997) Role of sensoryevoked NMDA plateau potentials in the initiation of locomotion. Science 278: $1122-1125$.

18. Dubuc R, Brocard F, Antri M, Fénelon K, Gariépy JF, et al. (2008) Initiation of locomotion in lampreys. Brain Res Rev 57: 172-182.

19. Sirota MG, Viana Di Prisco G, Dubuc R (2000) Stimulation of the mesencephalic locomotor region elicits controlled swimming in semi-intact lampreys. Eur J Neurosci 12: 4081-4092.

20. Le Ray D, Brocard F, Bourcier-Lucas C, Auclair F, Lafaille P, et al. (2003) Nicotinic activation of reticulospinal cells involved in the control of swimming in lampreys. Eur J Neurosci 17: 137-148.

21. Brocard F, Dubuc R (2003) Differential contribution of reticulospinal cells to the control of locomotion induced by the mesencephalic locomotor region. J Neurophysiol 90: 1714-1727.

22. El Manira A, Pombal MA, Grillner S (1997) Diencephalic projection to reticulospinal neurons involved in the initiation of locomotion in adult lampreys Lampetra fluviatilis. J Comp Neurol 389: 603-616.

23. Perret C, Millanvoye M, Cabelguen JM (1972) [Ascending spinal messages during fictitious locomotion in curarized cats]. J Physiol (Paris) 65: 153A.

24. Grillner S, McClellan A, Sigvardt K, Wallén P, Wilén M (1981) Activation of NMDA-receptors elicits "fictive locomotion" in lamprey spinal cord in vitro. Acta Physiol Scand 113: 549-551.

25. Rossignol S, Dubuc R, Gossard JP (2006) Dynamic sensorimotor interactions in locomotion. Physiol Rev 86: 89-154.

26. Ménard A, Auclair F, Bourcier-Lucas G, Grillner S, Dubuc R (2007) Descending GABAergic projections to the mesencephalic locomotor region in the lamprey Petromyzon marinus. J Comp Neurol 501: 260-273.

27. Ménard A, Grillner S (2008) Diencephalic locomotor region in the lampreyafferents and efferent control. J Neurophysiol 100: 1343-1353.

28. Bastian J, Heiligenberg W (1980) Phase-sensitive midbrain neurons in Eigenmannia: neural correlates of the jamming avoidance response. Science 209: 828-831.

29. Viana Di Prisco G, Pearlstein E, Le Ray D, Robitaille R, Dubuc R (2000) A cellular mechanism for the transformation of a sensory input into a motor command. J Neurosci 20: 8169-8176.

30. Straka H, Dieringer N (2004) Basic organization principles of the VOR: lessons from frogs. Prog Neurobiol 73: 259-309.

31. Baier H, Scott EK (2009) Genetic and optical targeting of neural circuits and behavior-zebrafish in the spotlight. Curr Opin Neurobiol 19: 553-560.

32. Yoon H, Enquist LW, Dulac C (2005) Olfactory inputs to hypothalamic neurons controlling reproduction and fertility. Cell 123: 669-682.

33. Green W, Derjean D, Dubuc R, Zielinski B (2009) Odour induced spatial activity patterns in the olfactory bulb of the sea lamprey (Petromyzon marinus). Soc Neurosci Abstr 68.22.

34. Dubuc R, Bongianni F, Ohta Y, Grillner S (1993) Anatomical and physiological study of brainstem nuclei relaying dorsal column inputs in lampreys. J Comp Neurol 327: 251-259.

35. Viana Di Prisco G, Ohta Y, Bongianni F, Grillner S, Dubuc R (1995) Trigeminal inputs to reticulospinal neurones in lampreys are mediated by excitatory and inhibitory amino acids. Brain Res 695: 76-80.
36. Bussières N, Dubuc R (1992) Phasic modulation of transmission from vestibular inputs to reticulospinal neurons during fictive locomotion in lampreys. Brain Res 582: 147-153.

37. Polenova OA, Vesselkin NP (1993) Olfactory and nonolfactory projections in the river lamprey (Lampetra fluviatilis) telencephalon. J Hirnforsch 34: 261-279.

38. Zompa IC, Dubuc R (1996) A mesencephalic relay for visual inputs to reticulospinal neurones in lampreys. Brain Res 718: 221-227.

39. Pierre J, Mahouche M, Suderevskaya EI, Repérant J, Ward R (1997) Immunocytochemical localization of dopamine and its synthetic enzymes in the central nervous system of the lamprey Lampetra fluviatilis. J Comp Neurol 380: 119-135.

40. Jordan LM (1998) Initiation of locomotion in mammals. Ann N Y Acad Sci 860: 83-93.

41. Xu F, Schaefer M, Kida I, Schafer J, Liu N, et al. (2005) Simultaneous activation of mouse main and accessory olfactory bulbs by odors or pheromones. J Comp Neurol 489: 491-500.

42. Von Bartheld CS, Meyer DL, Fiebig E, Ebbesson SO (1984) Central connections of the olfactory bulb in the goldfish, Carassius auratus. Cell Tissue Res 238: 475-487.

43. Matz SP (1995) Connections of the olfactory bulb in the Chinook salmon (Oncorhynchus tshawytscha). Brain Behav Evol 46: 108-120.

44. Schmidt A, Roth G (1990) Central olfactory and vomeronasal pathways in salamanders. J Hirnforsch 31: 543-553.

45. Smithson KG, Weiss ML, Hatton GI (1992) Supraoptic nucleus afferents from the accessory olfactory bulb: evidence from anterograde and retrograde tract tracing in the rat. Brain Res Bull 29: 209-220.

46. Mestre N, Petter A, Bons N (1992) Systematisation of the olfactory bulb efferent projections in a lemurian primate: Microcebus murinus. J Hirnforsch 33: $173-184$.

47. Eisthen HL (1997) Evolution of vertebrate olfactory systems. Brain Behav Evol 50: 222-233.

48. Miyasaka N, Morimoto K, Tsubokawa T, Higashijima S, Okamoto H, et al. (2009) From the olfactory bulb to higher brain centers: genetic visualization of secondary olfactory pathways in zebrafish. J Neurosci 29: 4756-4767.

49. Martinez-Marcos A (2009) On the organization of olfactory and vomeronasal cortices. Prog Neurobiol 87: 21-30.

50. Sinnamon HM (1993) Preoptic and hypothalamic neurons and the initiation of locomotion in the anesthetized rat. Prog Neurobiol 41: 323-344.

51. Keil W, Von Stralendorff F, Hudson R (1990) A behavioral bio-assay for analysis of rabbit nipple-search pheromone. Physiol Behav 47: 525-529.

52. Thesen A, Steen JB, Doving KB (1993) Behaviour of dogs during olfactory tracking. J Exp Biol 180: 247-251.

53. Kimchi T, Xu J, Dulac C (2007) A functional circuit underlying male sexual behaviour in the female mouse brain. Nature 448: 1009-1014.

54. Koide T, Miyasaka N, Morimoto K, Asakawa K, Urasaki A, et al. (2009) Olfactory neural circuitry for attraction to amino acids revealed by transposonmediated gene trap approach in zebrafish. Proc Natl Acad Sci U S A 106: 9884-9889. 